Article

\title{
Demystifying Subjective Well-Being of Academically At-Risk Students: Case Study of a Chinese High School
}

\author{
Tianjun Cheng ${ }^{1,2}$, Jin Jin ${ }^{1}$ and Junjun Chen ${ }^{3, *}$ \\ ${ }^{1}$ School of Education Science, Nanjing Normal University, China; E-Mails: chengtianjun@njnu.edu.cn (T.C.), \\ 190601004@njnu.edu.cn (J.J.) \\ ${ }^{2}$ Centre for Sociology of Education, Nanjing Normal University, China \\ ${ }^{3}$ Department of Education Policy and Leadership, Education University of Hong Kong, Hong Kong; E-Mail: jjchen@eduhk.hk \\ * Corresponding author
}

Submitted: 31 May 2021 | Accepted: 30 August 2021 | Published: 13 October 2021

\begin{abstract}
Student subjective well-being (SWB) is increasingly incorporated into today's education policies and positive education movements. There is a growing interest in how well schools promote student well-being, especially for disadvantaged students, e.g., the academically at-risk, and which factors affect this process. This study investigates how teachers and academically at-risk students perceive SWB and its influential precursors in a high school in China. The influential precursors in the present research were allocated into four dimensions, namely contextual factors, school factors, family factors, and individual factors. Via semi-structured individual interviews with 12 teachers and 18 students for about one hour and content analysis of the interview data, the responses revealed that while students tended to have a superficial understanding of well-being, traditional concepts about studying, blind filial piety, peer relations, and self-efficacy were important factors shaping and influencing their SWB. These findings can inform the development of inclusive education policies concerning student SWB and the intervention and prevention systems of schools in both local and international contexts. Recommendations for organising lectures for parents and implementing programs providing instruction on SWB-related skills for students are proposed to support academically at-risk students, aiming to achieve the educational goal of success for all.
\end{abstract}

\section{Keywords}

academically at-risk students; China; inclusive education; sociology of education; subjective well-being

Issue

This article is part of the issue "Promoting Inclusion and Equality in Education" edited Allen Thurston (Queen's University Belfast, UK) and Tien-Hui Chiang (Anhui Normal University, China).

(C) 2021 by the authors; licensee Cogitatio (Lisbon, Portugal). This article is licensed under a Creative Commons Attribution 4.0 International License (CC BY).

\section{Introduction}

School education should not only concern cognitive output but also attend to student well-being (Seligman, 2011). Studies show that student well-being is vital for their learning process, and high-quality subjective wellbeing (SWB) is always linked to better physical health, better interpersonal relationships, and a lower risk of psychological problems (Diener et al., 2018). SWB also leads to intrinsic motivation, internal locus of control and fewer school-discipline problems (Bücker et al., 2018).
Given the importance of well-being, the discourse of student SWB has been gaining impetus recently, especially in the fields of education, health, child protection, and policymaking (McLeod \& Wright, 2015).

The current situation of student SWB in China appears unrevealed. According to PISA 2018 data, only $59 \%$ of students from mainland China reported satisfaction with their lives, which is lower than the average percentage of the OECD countries of 67\% (OECD, 2019). However, studies on student SWB conducted in China are rare. Most previous studies focused only on one or 
a few influential SWB factors, resulting in a lack of understanding of which factors influence SWB and how they do so (Jia, 2020). Furthermore, there is a critical need for research on the SWB of high school students because, at ages ranging from 16 to 18 years old, they are more likely to experience SWB difficulties than younger students. Moreover, at this age, typically, they apply for university and thus experience enormous pressure coupled with precipitous social change in their lives (Graham et al., 2016). As a result, high school students, especially academically at-risk ones, may experience more academic pressure and a lower level of SWB (Bücker et al., 2018). One of the main ways to evaluate SWB has been through self-report rating scales; however, this approach may contain biases and provide limited access to the personal feelings and emotions of students (Diener et al., 2018). Accordingly, this project targets academically at-risk students aiming to understand the current state and influential factors of their SWB in a high school in China.

\section{Literature Review}

\subsection{Conceptualising Subjective Well-Being}

Although philosophers and researchers have explored human well-being for millennia, no clear consensus has been reached on its definition. Researchers tend to deem it as a complex concept with multiple dimensions related to health, psychology, and quality of life (Ryan \& Deci, 2001). SWB is a term frequently mentioned when well-being is investigated. In 1969, Bradburn gave momentum to the investigation of well-being by defining SWB as the relationship between positive and negative emotions (Hascher, 2008). Extending from this, Diener (1984) argued that SWB should include both a reflective evaluation of life (e.g., life satisfaction) and emotional responses to life. He equated SWB to happiness and divided it into three dimensions: positive affect, negative affect, and global life satisfaction (Diener et al., 2018). Extensive studies have been carried out in school contexts (e.g., Govorova et al., 2020). In addition to positive feelings and life satisfaction, self-optimisation, potential actualisation, and goal achievement have also been proposed as key elements of student SWB (Borgonovi \& Pál, 2016). However, because most of these seminal studies on SWB have been conducted outside of China-the context of the present study - they have not addressed its unique cultural, social, and educational background. Specifically, Lu (2010) pointed out that China is a collectivist nation and is largely influenced by Confucian philosophy. Accordingly, unlike western countries, the notion of "I" has long been obscured in traditional Chinese concepts and well-being is more associated with societal obligation and social embeddedness. Jia (2020) proposed that, since ancient times, Chinese people have attached great importance to studying. Therefore, academic success has been deemed as the crowning glory. Besides, his research findings indicate that the Chinese education system is characterised by severe competition, heavy academic burden and high-stake examination. Given these facts, more insight is needed to understand how Chinese students conceptualise well-being.

Historically, two distinct, yet complementary paradigms have developed in the research field of well-being. One is called "hedonism," proposed by a Greek philosopher named Aristippus who advocated maximising pleasure in life and believed that happiness was the sum of all the hedonic moments (Ryan \& Deci, 2001). Early followers of this philosophical hedonism emphasised the pursuit of bodily pleasure, human appetites, and self-interests (Kahneman et al., 2003) while, later on, preferences and pleasure of mind were also taken into account by psychologists (Ryan \& Deci, 2001). The other paradigm was termed "eudemonism" by Aristotle, who identified happiness with living well and the highest good (Ryan \& Deci, 2001). Eudemonia is achieved through virtuous actions and fulfilment of ones' potential. Extended from this, Waterman (1993) maintained that the eudemonic conception of well-being was related to activities that enable personal growth and improvement. Ryff (1995) believed that well-being was achieved through personal perfection and potential realisation. Although some researchers equated SWB to hedonic well-being (Kahneman et al., 2003), others criticised this simplified notion for failing to uncover the complexity and philosophical concepts of SWB (Berezina et al., 2020). Berezina et al. (2020) proposed to endorse a eudemonic view while investigating SWB by listing three main factors that foster SWB, namely pleasure, meaningful activities, and engagement. For students in the present research, in addition to immediate pleasure and subjective happiness, meaningful actions, such as the pursuit of goals and personal striving, which fall into the eudemonic paradigm, are also crucial constituents of their life and contribute to their well-being. As such, a synthesis of these two paradigms is employed to understand student SWB.

\subsection{Influential Factors of Student Subjective Well-Being}

Although high-quality SWB is desirable, how it can be achieved is complex. Pollard and Lee (2003) identified five domains of student well-being, and they are respectively physical, economic, psychological, cognitive and social. The operational measurement model of student well-being by Fraillon (2004) was classified into two dimensions: the intrapersonal dimension and interpersonal dimension. A review by Diener et al. (2018) summarised the most frequently researched factors underpinning SWB, including genetic effects, fulfilling of needs, income, life circumstances and community, and societal factors - these aspects could be further categorised into subjective factors and objective factors (Jia, 2020). The above research findings helped to clarify the composition and measurement construct of SWB technically, however, they may not be the best choice when the 
respondents' experience and feelings are required to understand their SWB. Kahneman et al. (2004) proposed a bottom-up theory that posits that the SWB level of each specific domain of one's life contributes to the overall SWB. This approach proved to be effective in producing accurate emotion recall and will be used in the present project. Factors are categorised into four domains, namely contextual, school, family and individual aspects.

\subsubsection{Contextual Factors}

Contextual factors, e.g., social, cultural, and organisational, can affect student SWB (Diener et al., 2018). Cross-cultural research has found that people tend to be happier if they possess a character that is highly valued in society and the domains that are value-congruent account for a larger proportion of SWB than the less valued congruent domains (Oishi et al., 1999). Researchers have also discovered that the value of academic excellence is a key moderator when the relationship between academic achievement and student SWB has been investigated (Bücker et al., 2018). Traditionally in China, school success is of great importance, leading to Chinese students suffering great pressure and anxiety while studying for examinations (Huang \& Zhou, 2019). Thus, such traditional values are noteworthy factors for SWB.

\subsubsection{School Factors}

Scholars have identified several school factors that have an impact on student SWB. These include school conditions (Merga, 2020), school-levelled policies (Shek \& $\mathrm{Wu}, 2016$ ), class composition by age and ability (Belfi et al., 2012), justice in the classroom (Honneth, 2004), and academic stress (Zhu, 2020). One study showed that a supportive learning context enhances adolescents' happiness (Hascher, 2008). Similarly, Jia (2020) found that, in China, a cooperative rather than a competitive climate was more beneficial for student SWB. Further, he claimed that a heavy academic burden can lead to students' academic pressure and a low level of SWB. Therefore, a supportive learning context with a lower academic burden can reduce students' anxiety and dissatisfaction.

\subsubsection{Family Factors}

Family factors, such as parents' educational and vocational background (Ge, 2015), family support (both tangible and intangible; Schnettler et al., 2014), family configuration (Potter, 2010), and parenting style (Stavrulaki et al., 2020) are all predictors of student SWB. For example, research findings have indicated that parenting style, characterised by caring and empathic parents devoid of excessive intrusion and infantilisation, is correlated with good family functioning and high-quality SWB (McFarlane et al., 1995). A Chinese study also found parents' educational background was linked to student
SWB (Ge, 2015). In conclusion, family plays a vital role in high school students' lives and nearly every aspect of family is closely connected with student SWB.

\subsubsection{Individual Factors}

Several personal factors including age, gender, temperament, and ethnicity, have been shown to have an impact on SWB (Diener et al., 2018). Preliminary investigations have revealed that there are consistent and robust associations between SWB and positive traits, for instance, love, zest, curiosity, gratitude, and high selfefficacy (Peterson et al., 2005; Strobel et al., 2011), and a higher level of SWB was discovered among female students (Shek \& Lin, 2017) and younger students (Elmore \& Huebner, 2010). Some research findings have shown that there is a positive correlation between personal academic functioning and student SWB (Steinmayr et al., 2015). Similar results were also found in China. For example, by analysing data from PISA 2018, Jia (2020) showed that students with a lower reading score had a lower level of SWB assessed by their sense of belonging. This finding illustrates that academically at-risk students may need more attention and care. Despite this finding, however, few studies have been conducted regarding student SWB. Thus, this project aims to achieve a deeper understanding of the current situation regarding the SWB of academically at-risk students guided by the following research questions: How do teachers and academically at-risk students perceive SWB in a high school in mainland China? What factors influence the SWB of academically at-risk high school students?

\section{Method}

This study used in-depth semi-structured interviews to answer the research questions.

\subsection{Sample and Instrument}

A convenience sampling of 12 teachers and 18 students from a high school in mainland China was approached through professional connections (Table 1). The sample school is of medium level among all the high schools in the city. It provides a diverse sample of students, defined in terms of their academic performance and family backgrounds. After briefing the principal about the project, we obtained permission to recruit teacher and student participants voluntarily. The sample teachers were recommended and coordinated by the principal. Among the 12 teachers, there were four males and eight females. Nine had bachelor's degrees and three had master's degrees. The sample students were selected by their class teachers. All students should rank in the bottom $20 \%$ of the class and therefore were considered academically at-risk based on their academic grades. The sample of 18 students consisted of five boys and 13 girls ranging from 15 to 17 years old $(M=15.8)$. At first, the student 
sample was intended to cover all three grades to make it more diversified. However, considering the high pressure and heavy work in the third year, the principal suggested only choosing students from the first two years, and eventually, the student sample consisted of nine students in their first year and nine in their second year.

The interview protocol consisted of two main issues: (a) participants' understanding of SWB and (b) the factors that affect the SWB of academically at-risk students. Each interview, conducted individually, lasted for about one hour and was audio-recorded with participants' permission beforehand. The participants' demographic information (e.g., age, gender, grade) was also taken into consideration to gain a better understanding.

\subsection{Data Analysis}

Content analysis was employed to analyse the data to make valid inferences (see Elo et al., 2014). In text coding, the teacher participants were labelled T1-T12 and student participants S1-S18. We used a code (P1, P2, etc.) to indicate the page number for all interview data and the same rules were used for the line numbers. The two research questions were employed to code the data. The deductive analysis involved four phases, namely preparing, organising, reporting and checking (Elo et al., 2014). In these phases, the unit of analysis was selected, coded, tested and discussed (Table 2).

\section{Findings}

Our coding of the interview transcripts generated the findings and in each of the following sections, teachers' opinions will be presented first, followed by students' perceptions.

\subsection{Conceptualisation and Current Situation of Subjective Well-Being of Academically At-Risk Students}

The teacher participants stated their understanding of student SWB and the student participants also shared their perceptions. From the teachers' perspective,

Table 1. Backgrounds of the participants.

\begin{tabular}{llllll}
\hline Teacher No. & Gender & Age & Years in teaching & Teaching subject & Academic qualification \\
\hline Teacher 1 & F & 42 & 20 & Chinese & Bachelor \\
Teacher 2 & F & 45 & 22 & History & Master \\
Teacher 3 & F & 43 & 21 & Physics & Bachelor \\
Teacher 4 & F & 47 & 24 & Chemistry & Master \\
Teacher 5 & F & 48 & 24 & Chemistry & Master \\
Teacher 6 & M & 48 & 25 & English & Bachelor \\
Teacher 7 & F & 34 & 8 & Biology & Bachelor \\
Teacher 8 & F & 50 & 26 & Chinese & Bachelor \\
Teacher 9 & F & 38 & 16 & English & Bachelor \\
Teacher 10 & M & 40 & 17 & Mathematics & Bachelor \\
Teacher 11 & M & 54 & 32 & Physics & Bachelor \\
Teacher 12 & M & 51 & 29 & & Bachelor
\end{tabular}

\begin{tabular}{|c|c|c|c|c|}
\hline Student No. & Gender & Grade & Age & Only child? \\
\hline Student 1 & $M$ & 1 & 16 & $Y$ \\
\hline Student 2 & $F$ & 1 & 15 & $\mathrm{~N}$ \\
\hline Student 3 & $M$ & 1 & 15 & $\mathrm{~N}$ \\
\hline Student 4 & $M$ & 1 & 15 & $\mathrm{~N}$ \\
\hline Student 5 & $F$ & 1 & 16 & $\mathrm{~N}$ \\
\hline Student 6 & $\mathrm{~F}$ & 1 & 15 & $Y$ \\
\hline Student 7 & M & 1 & 16 & $\mathrm{~N}$ \\
\hline Student 8 & $F$ & 1 & 15 & $\mathrm{~N}$ \\
\hline Student 9 & $\mathrm{~F}$ & 1 & 16 & $\mathrm{~N}$ \\
\hline Student 10 & $\mathrm{~F}$ & 2 & 16 & $\mathrm{~N}$ \\
\hline Student 11 & $F$ & 2 & 16 & $\mathrm{~N}$ \\
\hline Student 12 & $M$ & 2 & 17 & $\mathrm{Y}$ \\
\hline Student 13 & $F$ & 2 & 16 & $Y$ \\
\hline Student 14 & $\mathrm{~F}$ & 2 & 16 & $\mathrm{~N}$ \\
\hline Student 15 & $F$ & 2 & 16 & $\mathrm{~N}$ \\
\hline Student 16 & $F$ & 2 & 16 & $\mathrm{~N}$ \\
\hline Student 17 & $F$ & 2 & 17 & $Y$ \\
\hline Student 18 & $\mathrm{~F}$ & 2 & 16 & $\mathrm{~N}$ \\
\hline
\end{tabular}


Table 2. Excerpts from the interviews about student SWB and its influential factors.

\begin{tabular}{|c|c|c|}
\hline Influential factors of SWB & Teachers & Students \\
\hline Contextual factors & $\begin{array}{l}\text { Students are judged only by their academic } \\
\text { scores and I think this has something to do } \\
\text { with traditional Chinese concepts } \\
\text { (T3-P12-L22). }\end{array}$ & $\begin{array}{l}\text { I like dancing, but my parents didn't allow } \\
\text { me to attend dance classes because they } \\
\text { thought it would distract me from studying } \\
\text { (concepts about studying; S18-P5-L5). }\end{array}$ \\
\hline School factors & $\begin{array}{l}\text { Peer relations are more important compared } \\
\text { to other relationships at this age. Peers' } \\
\text { recognition and acceptance will greatly } \\
\text { enhance student SWB (T7-P2-L12). }\end{array}$ & $\begin{array}{l}\text { The school timetable is not reasonable. } \\
\text { I have to get up very early every morning } \\
\text { and I feel tired (S7-P1-L43). }\end{array}$ \\
\hline Family factors & $\begin{array}{l}\text { Most parents foster high hopes for their } \\
\text { children without considering their } \\
\text { competence (T12-P5-L15). }\end{array}$ & $\begin{array}{l}\text { I feel really depressed. My parents control } \\
\text { me in every aspect of my life, and I am like } \\
\text { under their intense surveillance. It makes me } \\
\text { feel like I am a prisoner (parenting style; } \\
\text { S8-P2-L35). }\end{array}$ \\
\hline Individual factors & $\begin{array}{l}\text { SWB is related to self-expectation. Students } \\
\text { who have high expectations for themselves } \\
\text { show a low level of SWB (T1-P6-L1). }\end{array}$ & $\begin{array}{l}\text { Of course, a low academic score affects my } \\
\text { mood, but it won't last for long. I always } \\
\text { recover from the sadness soon. What I will } \\
\text { do is to identify the problem and try to solve } \\
\text { it (character; S1-P2-L30). }\end{array}$ \\
\hline
\end{tabular}

SWB refers to subjective positive feelings. As one teacher shared:

Well-being is feeling happy. The criteria for it are personalised. For example, when you are satisfied with your life, then you enjoy high SWB. It does not matter how others conceive it. (T11-P1-L34)

He added later that SWB was also related to a meaningful life and peaceful state, and sometimes required restraint:

Well-being is not only about enjoyment or indulgence. It should also be related to inner peace and a harmonious state. But that does not mean people should be content with the status quo and make no progress. Try to enrich your life and experience and that will bring you true happiness. (T11-P6-L10)

Another teacher pointed out the discrepancy between high school students and adults regarding the conceptualisation of SWB:

Students' understanding of SWB tends to be superficial. Their happiness usually comes from some trivial things, for example eating delicious food or playing computer games. They do not think that some meaningful activities can bring happiness, for example studying and goal pursuing. (T9-P1-L37)

To some extent, this opinion could be verified by the students' answers. As one student shared:
Welling-being is doing what I like to do, such as chatting and hanging out with friends, reading novels and playing computer games. (S1-P2-L3)

It can be seen that both teachers and students agree that SWB is concerned with mental and bodily pleasure, which coincides with the hedonic psychology of wellbeing. However, teachers could easily identify well-being achieved through meaningful actions, whereas students mainly focus on the instant and superficial pleasure of their body and mind. Students' concept of well-being is more associated with being relaxed and away from problems. Very few students recognised and mentioned pleasure in meaningful activities and hard efforts. One student recalled:

I think well-being is a kind of feeling. For example, yesterday, I encountered a difficult question while doing homework. I spend a lot of time figuring out the answer, trying different methods and consulting the textbooks, and finally I made it. At that time, I felt a strong sense of well-being. (S3-P2-L5)

According to the eudemonic view, some experience, though challenging and laborious, could also bring SWB by achieving personal growth and fulfilling valuable tasks.

Apart from personal experience and emotions, some students also mentioned the connection between SWB and relationships with others. One student shared:

SWB comes from a good relationship with people around you. I am a sensitive person, and my emotions are easily influenced by others. I always feel happy 
when I am accompanied by my friends or I get along well with others. (S17-P6-L23)

It can be seen that interpersonal relationship is a key element of SWB. For students, it includes relationships with peers, teachers and parents.

Concerning the current state of SWB of the academically at-risk students, most teachers held a comparatively negative opinion. They believed that academic performance did have a considerable impact on student SWB. A teacher conveyed:

I think, in general, academically at-risk students will experience a lower level of SWB. After all, their main task at this moment is studying. Academic success may bring students more confidence and recognition from others. (T2-P3-L23)

However, the attitudes of students were quite different. Though the students interviewed were academically at-risk students, they did not seem too bothered by their academic performance and held quite a positive opinion about it:

Of course, a low academic score affects my mood, but it won't last for long. I always recover from the sadness soon. What I will do is to find out the problem and try to solve it. (S1-P2-L30)

While talking about their current state of SWB, male and female students demonstrated different responses. Male students tended to be reserved and gave positive answers and simple explanations, like "I feel quite happy" and "everything is going on well" (S1-P1-L40). Female students, however, were more willing to express their negative emotions and share their problems and confusion. One reason for this may be that, for Chinese students, boys are expected to be strong so they tend to hide their weaknesses in front of strangers.

\subsection{Factors Influencing Subjective Well-Being of the Academically At-Risk Students}

Teachers and students identified several influential factors of student SWB and shared examples. Factors are organised into four aspects, namely: contextual factors, school factors, family factors, and individual factors.

\subsubsection{Contextual Factors}

The contextual factors reported include traditional concepts, values and social norms. Most teachers stated that traditional Chinese beliefs about studying are a key contextual factor. One teacher recalled:

One student in my class wants to be a chef, but his parents do not agree. From his parents' perspective, being a chef is not a decent job. They want him to be a doctor or work for the government. They ask him to concentrate on studying to get into a good university. (T12-P5-L13)

Another teacher also pointed out that "students are judged only by their academic score and... this has something to do with traditional Chinese concepts" (T3-P12-L22). Traditional credentialism has considerable influence on students, for example, academic scores become the only criteria to evaluate a person and entering university becomes a unified goal for all students without considering their interests and abilities. A female student also recalled a similar unhappy story with her parents:

I like dancing but my parents didn't allow me to attend dance classes because they thought it would distract me from studying..... have tried to talk to my parents and persuade them, but I failed. They are my parents after all, and I have to obey them. (S18-P5-L5, S18-P5-L7)

In this excerpt, the students unwillingly acquiesced to their parents' demands despite having different opinions. This phenomenon is very common in Chinese families and it should not only be attributed to the traditional authoritarian and controlling parenting style but also to the culture and norms in Chinese society.

Many of the interview responses demonstrated that parents' traditional beliefs about studying and blind filial piety reduce students' life satisfaction.

\subsubsection{School Factors}

The factors related to school include the school environment, academic stress and peer relations. The teachers stated that a fair and just environment is vital for students, especially for the academically at-risk ones. For example, a teacher reported:

Teachers tend to pay more attention to highperforming students by giving them more guidance and instructions, but sometimes the academically atrisk students are more in need of attention and a little praise or even some eye contact would make them feel like they are being equally treated and cared about. (T7-P2-L2)

Classroom discrimination and unfair treatment can put students in a marginalised position. The academically atrisk students, though sometimes appearing nonchalant, are still in desperate want of equal attention from teachers. Peer relation is another key factor related to school, with most teachers stating that it had a great impact on student SWB. For example, one teacher stated:

Peer relations are more important compared to other relationships at this age. Peers' recognition 
and acceptance will greatly enhance student SWB. Students who can get along well with their classmates are usually in a positive mood and a good mental state. (T7-P2-L12)

Peer relation was also identified by students as a key influential factor in their well-being. A girl shared:

My classmates are quite friendly and helpful. For example, if I have trouble with my studies, they won't laugh at me but tell me how to solve it patiently.... l like school because I can stay with my friends here. (S13-P3-L9)

Both teachers and students highlighted the importance of peer relations. Good peer relations promote student well-being and make students feel welcome and included at school. However, some students reported having interpersonal problems, for example, "being bullied," "being gossiped about," and thus "experiencing a tough period" (S8-P7-L17). School bullying is not a rare phenomenon and was reported by a few students. The bullying tactics included social exclusion and rumour-spreading, which can impair student SWB by destroying their confidence, making them feel isolated, and even arousing a hatred for school.

Policies and regulations were also mentioned by students. One student complained that "the school timetable is not reasonable. I have to get up very early every morning and I feel tired" (S7-P1-L43). According to the student, the morning class begins at $6.40 \mathrm{AM}$. Some students live far away from school and it takes more than one hour on the road. So, they have to get up at around 5 AM. Insufficient sleep and long commutes not only exhaust students but also damage their health. According to previous research, physical health is a major constituent of SWB (Pollard \& Lee, 2003).

In the excerpts above, teachers appear more concerned with classroom justice or the whole environment of the class while students pay more attention to peer relationships or school regulation. The reason may be that they are in different positions: teachers are regulators of their classes while students are members of them. Thus, both class circumstances and peer relations are significant indicators for SWB.

\subsubsection{Family Factors}

Family factors consist of parenting style, family support, family configuration, and parents' educational and vocational background. From the teachers' perspective, high parental expectations regarding academic performance are the main precursor for students' unhappiness in the Chinese context. As stated by one teacher:

Most parents foster high hopes for their children without considering their competence. From Chinese parents' perspective, being admitted into university is glorious while entering higher vocational college is shameful. Such vanity will bring enormous pressure for students, especially for the academically at-risk. (T12-P5-L15, T12-P5-L18)

Influenced by credentialism, parents sometimes hold expectations beyond their children's ability and are difficult for them to live up to. The resulting dissatisfaction can give rise to low student SWB.

Parenting style is the family factor that was most frequently mentioned by students. They complained about the authoritarian and controlling parenting style and deemed it as a sign of distrust and disapproval:

I feel really depressed. My parents control me in every aspect of my life and I am, like, under their intense surveillance. It makes me feel like I am a prisoner and I am not trustworthy. (S8-P2-L35)

Teenagers at this stage are at a critical period in life when they need to be cared for and supported more than ever by their family; however, such a controlling parenting style can deprive students of their autonomy and make them feel like they are not being trusted. The interview responses demonstrated that family plays an important role in students' SWB with parental expectations and parenting style being the most crucial factors.

\subsubsection{Individual Factors}

Personal factors such as age, gender, character and academic functioning have an impact on SWB. However, academic performance was seldom identified as the key influential factor, despite the teachers attaching great importance to self-efficacy. They collectively stated students should be able to establish goals and feel confident in achieving them, and during the process, their SWB should be promoted. One teacher shared his thoughts on this:

It is important for students to have clear short-term or long-term goals. Life in high school is stressful and exhausting as students are overwhelmed with loads of work and exams. A clear goal can help them realise the meaning and hope in their tedious lives. (T12-P1-L11)

Another teacher also suggested that SWB is related to self-expectation. He stated that "students who have high expectations for themselves show a low level of SWB" (T1-P6-L1). It should be noted that people with high expectations are more likely to establish challenging goals that are far beyond their competence. If their attempts failed, they would feel desperate and upset.

While discussing the future, most of the students had mixed feelings. On the one hand, they were looking forward to it, but on the other, they were at a loss. They had no goals or interests and were struggling in their tedious 
school life with low spirits. Only one student shared his dream proudly and excitedly:

I want to be a forensic scientist. This major requires students to study physics in high school. Although I am not good at it, I am trying my best to work on it and things will get better. (S8-P10-L28)

The data show that goal progress is a predictor of SWB enhancement and fewer symptoms of depression, while high self-efficacy regarding valued and suitable goals is usually linked with a high level of SWB.

\section{Discussion}

This article investigates the SWB of Chinese high school students. With a particular interest in academically at-risk students, the article provides insight into their understanding of SWB and its influential factors. Through a conscious examination of the unique cultural, social, and educational background in China, the concept of SWB in the Chinese context is elaborated. According to the major findings of the present study, there are three key influential factors of SWB in academically at-risk students, namely, traditional concepts, peer relations, and goal-pursuing. In the following sections, each of these aspects is analysed and discussed.

First, findings of this project indicate that traditional concepts play a vital role in shaping students' concepts of SWB and predicting its level, which coincides with previous findings showing that social values are a moderator for SWB (Oishi et al., 1999). However, few studies have explored how Chinese culture affects student SWB. Historically, Chinese people value learning. As an old saying goes "reading books is superior to everything." Under this way of thinking, the ultimate goal of learning is not to enrich one's life, but to be an official. This notion was shared by one teacher who said that parents hoped their children could get into a good university and work for the government. However, for a large number of students, such expectations from parents are too high to satisfy.

On one hand, there is fierce competition in the college entrance examination in China. According to the data published by the Ministry of Education of the People's Republic of China, in 2020, the gross enrolment rate in higher education (including university, college, and higher vocational education) is only $54.4 \%$ (Ministry of Education of the People's Republic of China, 2021). That means nearly half of students were rejected by universities or colleges and did not have the chance to receive higher education. The result coincides with previous findings from research in China (e.g., Jia, 2020; Zhu, 2020). On the other hand, academically at-risk students are in an unfavourable position in this competition, because of their limited competence in studying and competitiveness in exams illustrated by their previous academic performance. Thus, irrational expectations from parents would cause more pressure and anxiety for them and destroy their well-being.

Another factor related to social values is parenting style. In Confucian societies, filial piety is deemed as the guiding principle governing socialisation. Influenced by this traditional belief, a relatively authoritarian and controlling parenting style is prevalent in Chinese families (Lieber et al., 2006). This parenting style is featured by mandatory rules, absolute obedience, and less reciprocal parent-child communication. Even when ones' parents' opinion is unreasonable, children must obey them when disagreement occurs, attested to by the girl interviewed in this project who gave up her dancing. Obeying and honouring one's parents unconditionally is an unyielding principle (Ho, 1994). In this process, children lose their true selves and are deprived of autonomy. From the eudemonic perspective of well-being, autonomy is both a key element of well-being and a basic psychological need. Fulfilling such needs fosters psychological growth and SWB (Ryan \& Deci, 2001). However, an authoritarian parenting style constricts autonomy and relations with parents, which can impair student SWB (Yeh \& Bedford, 2003).

Second, peer relations were reported by most students as affecting their SWB, in line with previous research (Hascher, 2008). An investigation in Hong Kong also highlighted the ultimate primacy of relationships on Chinese SWB (McAuley et al., 2004) because of the emphasis on interdependence in Chinese society ( $\mathrm{Lu}$, 2010). Although research on students in the West has noted the importance of peer relationships on student SWB (e.g., Belfi et al., 2012), social failure is more devastating in the Chinese context. One reason for this could be that China is a collectivist nation. The concepts of "I" and "true self" remain vague for Chinese students and are inherently bound to others. Consequently, the Chinese paradigm of well-being is socially oriented, emphasising more on the welfare of the community and role obligations of individuals (Lu, 2010). In such circumstances, students will try their best to fit into school, family and society to seek harmony with the environment and pursue well-being at the same time. However, bad relations at school, such as being bullied, will jeopardise this interpersonal harmony and signals a failure of role-playing at school. It not only reduces student wellbeing but also arouses resentment for school, sometimes leading to psychological problems. The link between peer relationships and SWB may also be explained by Honneth's recognition theory (Honneth, 2004), which identifies three modes of recognition-love, rights and solidarity-and states that recognition is linked to happiness. This may explain why one student (in our interviews) felt happy about being helped by classmates. The student was slightly sensitive and felt inferior to others for not being good at studying, but her classmates did not laugh at her but warmly gave her support, which promoted her SWB by making her feel loved, respected, and acknowledged. 
Finally, one interesting finding is that academic achievement does not seem to be that important for the SWB of academically at-risk students. The data showed that academic performance was rarely reported by students as an influential factor in their happiness. This is contradictory to a previous study (Jia, 2020). Possibly, it was out of pride that students were unwilling to admit that they were troubled by their unsatisfactory academic performance. That is, they would act like they don't care. But more importantly, it could be inferred that it was the high self-expectation, instead of academic achievements, that had a direct impact on SWB. Academically at-risk students are not necessarily less happy, as supposed by the teachers in the interview, unless their self-expectation concerning studying is too high to be lived up to, and high achievers might also demonstrate a low level of SWB for not achieving their goal. In addition, among all individual factors, both teachers and students stressed the positive relationship between goal progress and SWB. In one excerpt, the student who described her dream of being a forensic scientist seemed excited and confident, which fits with previous theories about feelings of efficacy regarding goals leading to greater positive emotions and well-being (Ryan \& Deci, 2001). In the Chinese context, school education is characterised by severe competition and a heavy academic burden. Students, especially high school students, easily feel depressed under such intense pressure. According to the satisfaction of goal theories, clear goals can help individuals feel motivated and less depressed (Diener et al., 2018). When goals are achieved, SWB is also enhanced.

It could be seen from the findings that the constituents of hedonism, such as positive feelings, are important indicators of well-being, and the totality of such hedonic pleasure greatly influences students' evaluation of their whole life and their long-term SWB. Such findings are similar to previous results on hedonism (e.g., Ryan \& Deci, 2001). However, while investigating the influential factors of student SWB, most of them could be explained by the theory of eudemonism, for example, the factors related to goal-pursuing, autonomy, personal growth, recognition from others and fulfilment of one's potential. Even though SWB emphasises subjective individual feeling, the eudemonic approach provides a more profound insight into the understanding of well-being and makes it justified and possible to promote SWB by giving guidance and support. These results are different from some previously observed (e.g., Kahneman et al., 2003), but similar to others (e.g., Berezina et al., 2020; Ryff, 1995).

\section{Implications and Conclusion}

Based on the findings of this project, implications can be drawn for parents, teachers and policymakers. The study can contribute to the understanding of the current situation and the influential factors of SWB affecting academically at-risk high school students. The findings can also help inform the development of inclusive education policies related to student SWB. We found that traditional beliefs held by parents may be impairing student SWB; therefore, lectures for parents should be organised to help them acquire more appropriate parenting skills. Curricula and programs for students should also be implemented at schools to give instructions on skills related to SWB, for example how to deal with peer relations. The research findings also highlight the value of defining goals and goal pursuit in improving SWB. It is proposed that parents and teachers should pay more attention to the function of goals in improving student SWB. They are advised to help students to find their interests and strengths and encourage them to establish an optimally challenging goal. The curriculum can also be formulated to give guidance on how to make plans to achieve the goals and how to deal with the problems that might be encountered in goal progression. These suggestions can give better support to academically at-risk students, helping to achieve the ultimate educational goal of success for all while promoting social inclusion and equality.

In sum, this study explores the SWB of Chinese high school students and uncovers how it is affected from both the students' and teachers' perspectives. We focused on academically at-risk students and carried out a comprehensive investigation based on various aspects of their life. Limitations should be noted. First, the project used only one school as a case study, which cannot ensure the generalisability of the findings and may lead to sample bias. In the future, multiple case studies could be carried out to achieve greater validity, and more schools and other types of students (e.g., elite students) could be investigated so that comparisons between them may be made. Another limitation of the present research would be over-reliance on interviews. Although interviews could give a relatively vivid and accurate depiction of participants' SWB, it is not always reliable. For example, sometimes it is unclear whether one problem posed by the interviewee is exaggerated or objectively reported. Thus, in future research, a mixed-method or observation research design may enrich the findings based on this kind of qualitative research. Finally, although our participants' responses indicate a different understanding of well-being, our emphasis in the current study is not on the social-cultural perspective. However, this should be explored in future studies in particular so that we can provide appropriate support to our students for better wellness.

\section{Acknowledgments}

The authors are grateful to the reviewers, who dedicated their time and expertise, for their valuable feedback on this article.

\section{Conflict of Interests}

The authors declare no conflict of interest. 


\section{References}

Belfi, B., Goos, M., De Fraine, B., \& Van Damme, J. (2012). The effect of class composition by gender and ability on secondary school students' school well-being and academic self-concept: A literature review. Educational Research Review, 7(1), 62-74.

Berezina, E., Gill, C. M. H. D., \& Bovina, I. (2020). A study of the association between identity, life engagement and well-being among young Asian adults. Social Identities, 26(5), 1-16.

Borgonovi, F., \& Pál, J. (2016). A framework for the analysis of student well-being in the PISA 2015 study: Being 15 in 2015. OECD Publishing.

Bücker, S., Nuraydin, S., Simonsmeier, B. A., Schneider, M., \& Luhmann, M. (2018). Subjective well-being and academic achievement: A meta-analysis. Journal of Research in Personality, 74, 83-94.

Diener, E. (1984). Subjective well-being. Psychological Bulletin, 95(3), 542-575.

Diener, E., Oishi, S., \& Tay, L. (2018). Advances in subjective well-being research. Nature Human Behavior, 2(4), 253-260.

Elmore, G. M., \& Huebner, E. S. (2010). Adolescents' satisfaction with school experiences: Relationships with demographics, attachment relationships, and school engagement behavior. Psychology in the Schools, 47(6), 525-537.

Elo, S., Kääriäinen, M., Kanste, O., Pölkki, T., Utriainen, K., \& Kyngäs, H. (2014). Qualitative content analysis: A focus on trustworthiness. SAGE Open, 4(1). https:// doi.org/10.1177/2158244014522633

Fraillon, J. (2004). Measuring student well-being in the context of Australian schooling: Discussion paper. Mceetya.

Ge, M. R. (2015). Fuqin zhiye yu xueli dui zhongxiao xuesheng xingfugan de yingxiang [The influence of fathers' occupation and education background on the wellbeing of students in the stage of primary and secondary education]. Jiaoyu yanjiu, 36(08), 133-138.

Govorova, E., Benítez, I., \& Muñiz, J. (2020). Predicting student well-being: Network analysis based on PISA 2018. International Journal of Environmental Research and Public Health, 17(11). https://doi.org/ 10.3390/ijerph17114014

Graham, A., Powell, M. A., \& Truscott, J. (2016). Facilitating student well-being: Relationships do matter. Educational Research, 58(4), 366-383.

Hascher, T. (2008). Quantitative and qualitative research approaches to assess student well-being. International Journal of Educational Research, 47(2), 84-96.

Ho, D. Y. F. (1994). Cognitive socialisation in Confucian heritage cultures. In P. M. Greenfield \& R. R. Cocking (Eds.), Cross-cultural roots of minority child development (pp. 285-314). Lawrence Erlbaum Associates.

Honneth, A. (2004). Recognition and justice: Outline of a plural theory of justice. Acta Sociologica, 47(4), 351-364.
Huang, Q., \& Zhou, R. L. (2019). Zhongguo xuehseng kaoshi jiaolv de fazhan qushi [The development trend of test anxiety in Chinese students]. Zhongguo linchuang xinlixue zazhi, 27(01), 113-118.

Jia, Y. (2020). Xuesheng xingfugan xianzhuang, yingxiang yinsu ji qishi [Student well-being: Current situation, influencing factors and enlightenment]. Jiaoyu fazhan yanjiu, 40(06), 36-42.

Kahneman, D., Diener, E., \& Schwarz, N. (2003). Wellbeing: The foundations of hedonic psychology. Russell Sage Foundation.

Kahneman, D., Krueger, A. B., Schkade, D. A., Schwarz, N., $\&$ Stone, A. A. (2004). A survey method for characterizing daily life experience: The day reconstruction method. Science, 306(5702), 1776-1780.

Lieber, E., Fung, H., \& Leung, P. W. L. (2006). Chinese child-rearing beliefs: Key dimensions and contributions to the development of culture-appropriate assessment. Asian Journal of Social Psychology, 9(2), 140-147.

Lu, L. (2010). Chinese well-being. In M. H. Bond (Ed.), The Oxford handbook of Chinese psychology ( $p p$. 327-342). Oxford University Press.

McAuley, P. C., Bond, M. H., \& Ng, I. W. C. (2004). Antecedents of subjective well-being in working Hong Kong adults. Journal of Psychology in Chinese Societies, 5(1), 25-49.

McFarlane, A. H., Bellissimo, A., \& Norman, G. R. (1995). Family structure, family functioning and adolescent well-being: The transcendent influence of parental style. Journal of Child Psychology and Psychiatry, 36(5), 847-864.

McLeod, J., \& Wright, K. (2015). Inventing youth wellbeing. In J. McLeod \& K. Wright (Eds.), Rethinking youth wellbeing (pp. 1-10). Springer.

Merga, M. K. (2020). School librarians as literacy educators within a complex role. Journal of Library Administration, 60(8), 889-908.

Ministry of Education of the People's Republic of China. (2021). 2020 nian quanguo jiaoyu shiye tongji zhuyao jieguo [The main results of national education statistics in 2020]. http://www.moe.gov.cn/jyb_xwfb/ gzdt_gzdt/s5987/202103/t20210301516062.html

OECD. (2019). PISA 2018 results (Volume III): What school life means for students' lives. OECD iLibrary. https:// doi.org/10.1787/acd78851-en

Oishi, S., Diener, E., Suh, E., \& Lucas, R. E. (1999). Value as a moderator in subjective well-being. Journal of Personality, 67(1), 157-184.

Peterson, C., Park, N., \& Seligman, M. E. P. (2005). Orientations to happiness and life satisfaction: The full life versus the empty life. Journal of Happiness Studies, 6(1), 25-41.

Pollard, E. L., \& Lee, P. D. (2003). Child well-being: A systematic review of the literature. Social Indicators Research, 61(1), 59-78.

Potter, D. (2010). Psychosocial well-being and the relationship between divorce and children's academic 
achievement. Journal of Marriage and Family, 72(4), 933-946.

Ryan, R. M., \& Deci, E. L. (2001). On happiness and human potentials: A review of research on hedonic and eudaemonic well-being. Annual Review of Psychology, 52(1), 141-166.

Ryff, C. D. (1995). Psychological well-being in adult life. Current Directions in Psychological Science, 4(4), 99-104.

Schnettler, B., Denegri, M., Miranda, H., Sepúlveda, J., Orellana, L., Paiva, G., \& Grunert, K. G. (2014). Family support and subjective well-being: An exploratory study of university students in southern Chile. Social Indicators Research, 122(3), 833-864.

Seligman, M. E. P. (2011). Flourish. Simon \& Schuster.

Shek, D. T. L., \& Lin, L. (2017). Trajectories of personal well-being attributes among high school students in Hong Kong. Applied Research in Quality of Life, 11(4), 1-26.

Shek, D. T. L., \& Wu, F. K. Y. (2016). The project P.A.T.H.S. in Hong Kong: Work done and lessons learned in a decade. Journal of Pediatric and Adolescent Gynecology, 29(1), 3-11.

Stavrulaki, E., Li, M., \& Gupta, J. (2020). Perceived parenting styles, academic achievement, and life satisfac- tion of college students: The mediating role of motivation orientation. European Journal of Psychology of Education, 36, 693-717.

Steinmayr, R., Crede, J., McElvany, N., \& Wirthwein, L. (2015). Subjective wellbeing, test anxiety, academic achievement: Testing for reciprocal effects. Frontiers in Psychology, 6. https://doi.org/10.3389/fpsyg. 2015.01994

Strobel, M., Tumasjan, A., \& Sporrle, M. (2011). Be yourself, believe in yourself, and be happy: Self-efficacy as a mediator between personality factors and subjective well-being. Scandinavian Journal of Psychology, 52(1), 43-48.

Waterman, A. S. (1993). Two conceptions of happiness: Contrasts of personal expressiveness (eudaimonia) and hedonic enjoyment. Journal of Personality and Social Psychology, 64(4), 678-691.

Yeh, K. H., \& Bedford, O. (2003). A test of the Dual Filial Piety model. Asian Journal of Social Psychology, 6(3), 215-228.

Zhu, Y. (2020). Xueye chengjiu yu xuesheng xingfu kefou jiande? [Can academic achievements and student well-being exist concurrently?]. Zhongguo jiaoyu xuekan, 3(01), 21-27.

\section{About the Authors}

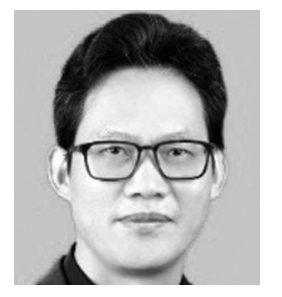

Tianjun Cheng (PhD) is the vice-principal of Nanjing Normal University, and the dean and Changjiang Scholar distinguished professor at the School of Education Science, Nanjing Normal University, China. $\mathrm{He}$ is the vice-president of the Chinese Association for Sociology of Education. His current research interests are sociology of education, educational policy, teacher professionalisation, and rituals in schooling.

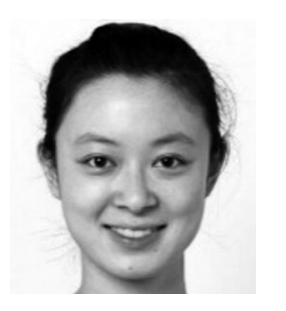

Jin Jin is a PhD student in the School of Education Science, Nanjing Normal University, majoring in educational studies. Her main research interests are sociology of education, student well-being, and language learning and education, with a particular focus on disadvantaged students. She did her MA at the University of York in language learning and education speciality.

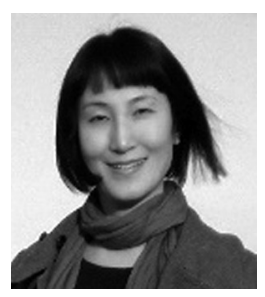

Junjun Chen is an associate professor in the Department of Education Policy and Leadership at the Education University of Hong Kong. Her current themes of research include teacher well-being and development, school principal well-being and development, systematic literature review, and psychometric measurement. 